\title{
Upper GI bleeding among neonates admitted to Mulago Hospital, Kampala, Uganda: a prospective cohort study
}

\author{
*Ombeva $\mathrm{OM}^{1,2}$, Ndeezi $\mathrm{G}^{1}$, Mugalu J ${ }^{1}$ \\ 1. Department of Paediatrics, Faculty of Health Sciences, Egerton University, P.O Box 536-20115, Egerton, \\ Nakuru, Kenya. \\ 2. Department of Paediatrics and Child Health, Makerere University Medical School, P.O Box 7072, Kampala.
}

\begin{abstract}
Background: The World Health Organization (WHO) reports estimate that $85 \%$ of newborn deaths are due to infections, prematurity and fetal distress. These conditions are risk factors for upper GI bleeding (UGIB) in sick neonates. UGIB is associated with poor neonatal outcomes such as prolonged hospitalisation and poor weight gain. The magnitude of UGIB and its contribution to neonatal morbidity has not been described in most low income countries.

Objective: To determine the occurrence and factors associated with UGIB among neonates admitted to the Special Care Unit (SCU) of Mulago Hospital.

Methods: This was a prospective single cohort study where neonates admitted within 24 hours of birth were consecutively enrolled and followed up for seven days. Gastric aspirates from the neonates were examined daily over a period of 7 days using Guaiac and Apt tests for evidence of UGIB. Data on occurrence of UGIB has been presented as proportions and Odds Ratios for associated factors.

Results: Out of 191 neonates, 44 (23\%) developed UGIB. Factors independently associated with UGIB included cyanosis in the neonate [OR 5.8; (95\% CI; 1.8 - 19.1) p-value 0.004], neonatal seizures [OR 12.6; (95\% CI 2.3 - 70.5); p-value 0.004] and birth asphyxia [OR 6.3; (95\% CI $1.9-21.6)$; p-value 0.003].

Conclusions: In the first seven days of life, UGIB occurred in 1:4 neonates. Factors independently associated with UGIB included birth asphyxia, cyanosis in the neonate and neonatal seizures.

Key words: Upper GI bleeding, Neonates, Uganda

African Health Sciences 2013; 13(3): 741 - 747 http://dx.doi.org/10.4314/ahs.v13i3.32
\end{abstract}

\section{Introduction}

Upper GI bleeding in neonates occurs in 10 to $40 \%$ of critically ill neonates, especially among those suffering from infections, preterm birth, thrombocytopenia and birth asphyxia ${ }^{1-4}$. This condition is associated with poor neonatal outcomes such as prolonged hospitalization and poor weight gain. Most of the published studies have been conducted in high income countries with better neonatal care and outcomes compared to the low income countries. The magnitude of UGIB bleeding and its contribution to neonatal morbidity have not been described in most low income countries. In this paper we describe the occurrence of UGIB in a neonatal unit at Mulago Hospital, Kampala, Uganda and associated factors.

\begin{tabular}{|l|}
\hline *Corresponding author: \\
Oliver M Ombeva \\
Current address: Department of Paediatrics \\
Faculty of Health Sciences, Egerton University \\
P.O Box 536-20115 \\
Egerton, Nakuru, Kenya \\
Tel : +254722 475181 \\
Email: ombevaom@gmail.com \\
\hline
\end{tabular}

African Health Sciences Vol 13 Issue 3 September 2013

\section{Methods}

\section{Study design and Setting}

This was a prospective cohort study, conducted in November and December 2010 at the Special Care Unit (SCU) of Mulago Hospital. Mulago Hospital is a national referral hospital for Uganda and the Teaching Hospital for Makerere University. The SCU, which serves as the neonatal intensive care unit, receives ill or preterm neonates of age less than 24 hours born in or referred to Mulago Hospital.

\section{Sample size estimation}

A sample size for occurrence of UGIB of 141 was based on a $10.2 \%$ prevalence of $\mathrm{UGIB}^{3}$ using Keish Leslie formula. Based on a reported association between thrombocytopenia and $\mathrm{UGIB}^{5}$, a sample size 173 for factors associated with UGIB was obtained using the Fleiss formula ${ }^{6}$. Adding 10\% loss to follow up to the larger sample size of 173 , a sample size of 191 was required for the study.

\section{Enrolment of patients}

All neonates admitted to the SCU during the study period were eligible for participation. Those whose 
mother/caretaker provided informed consent were enrolled. Babies born before arrival to hospital, those who already had UGIB at admission and neonates older than 24 hours at enrollment were excluded. Neonates were recruited every day between 8:00 am and $8: 00 \mathrm{pm}$, while those admitted after $8.00 \mathrm{pm}$ were recruited the following morning. All the participants had a detailed physical examination including gestation age assessment using the New Ballard's scoring system.

\section{Specimen collection and lab analysis}

All the neonates had an NG tube gauge 5 inserted. At least $2 \mathrm{ml}$ of gastric aspirates were collected once daily between 8-9.00 am and sent for occult blood analysis at the Clinical chemistry laboratory. Part of the sample from aspirates that tested positive for occult blood was subjected to an Apt test to determine the origin of the blood. Peripheral blood samples were taken for a complete blood count at the hematology laboratory of Mulago hospital.

\section{Follow up}

All the neonates in this study were followed up for seven days, or until they developed UGIB, or death or discharge or the attending doctors recommend removal of the NG tube, whichever came first.

\section{Data Management}

Data was collected using a structured questionnaire, entered into a database using EPI DATA 3.1 and analyzed using STATA version 10 . P-values below 0.05 were considered significant using confidence intervals of $95 \%$. Laboratory, maternal and infant characteristics were compared among infants who had UGIB versus those who did not have UGIB. Factors with a p-value of less than 0.1 were entered into logistic regression by backward stepwise method and tested for confounding and interaction to the independent variable.

\section{Ethical considerations}

Written informed consent was obtained from all the mothers of the participating neonates. Approval to carry out this study was obtained from the Institutional Research and Ethics committee of Makerere University Medical School, Mulago Hospital Ethics Committee and the Uganda National Council for Science and Technology.

\section{Results}

During the months of November and December 2010, three hundred and twenty six (326) neonates admitted to the SCU were screened, out of which 207 were eligible. As shown in figure 1, seven eligible neonates were excluded because 5 mothers refused to consent and 2 babies were abandoned and had no caretakers. A further 9 neonates were excluded from the analysis because of missing laboratory results. All the study subjects were less than 24 hours old at enrollment. The mean gestational age of the study participants was 35.0 weeks (SD 3.0) and the mean birth weight was $2.4 \mathrm{~kg}$ (SD 0.8). The other characteristics are shown in table 1.

\section{Laboratory findings of study subjects}

Of the 191 participants, 23 had a low platelet count of $<150,000 / \mu \mathrm{L}$. As shown in table 2 , a total of 92 neonates had a positive guaiac test in their gastric aspirates. Out of these 92 neonates, 44 had a negative Apt test, indicating that the blood in the aspirates was of neonatal origin; while 48 samples with positive Apt test contained swallowed maternal blood.

\section{Occurrence of UGIB}

In this study, $23.0 \%$ of the neonates followed up developed UGIB. A majority (59.0\%) of those 44 neonates were male and $59.1 \%$ were term babies.

\section{Factors associated with UGIB}

Table 3 shows the diagnosis, clinical and laboratory findings associated with UGIB on bivariate analysis. As shown in table 4, factors independently associated with UGIB include cyanosis in the neonate, neonatal seizures and birth asphyxia. 


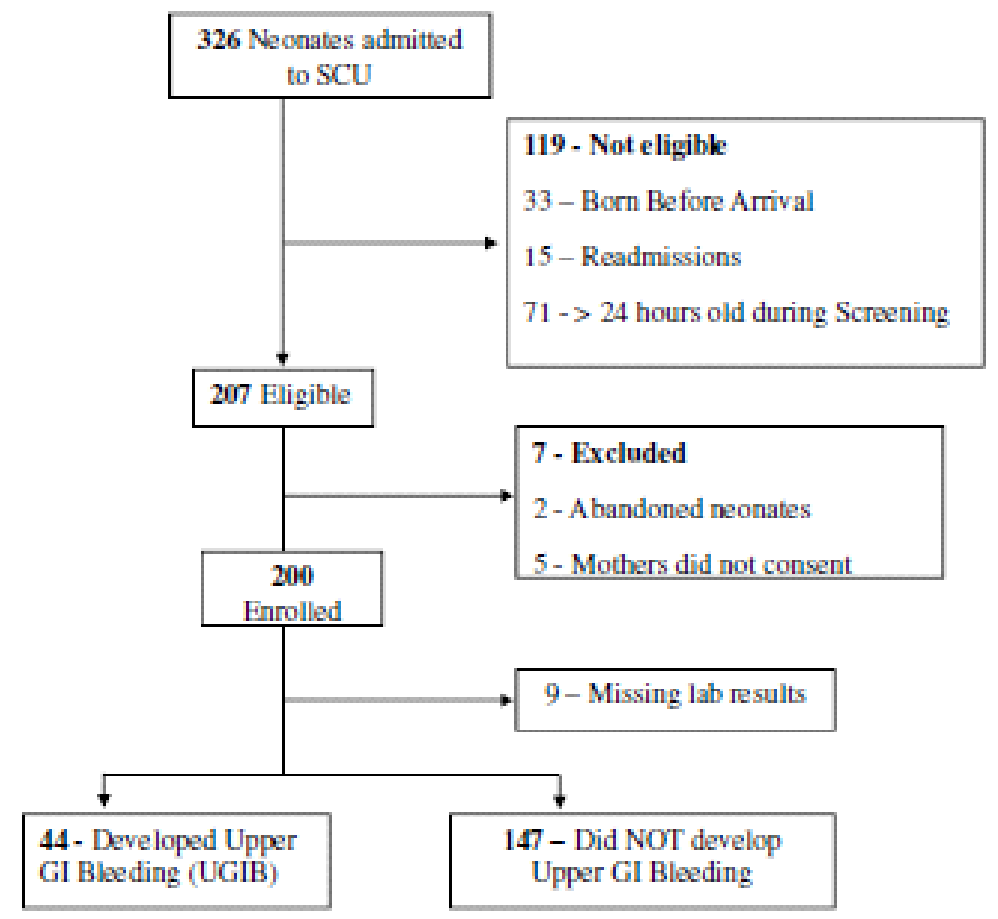

Figure 1: Study Profile

Table 1: Characteristics of the 191 neonates assessed for occurrence of UGIB

\begin{tabular}{lcc}
\hline Variable & Frequency(191) & Percentage(\%) \\
\hline Sex & & \\
Male & 103 & 54.0 \\
Female & 88 & 46.0 \\
Birth type & & \\
Single & 142 & 74.4 \\
Twin & 49 & 25.6 \\
Duration of Labor & & \\
Normal(< 18 Hours) & 100 & 52.4 \\
Prolonged $>$ 18 Hours) & 91 & 47.6 \\
Mode of delivery & & \\
Vaginal & 136 & 71.2 \\
Cesarean section & 55 & 28.8 \\
HIV exposure & & \\
Not exposed & 142 & 74.3 \\
Exposed & 33 & 17.3 \\
Unknown & 16 & 8.4 \\
Gestation Age & & \\
Preterm $(<37 \mathrm{wks})$ & 102 & 53.4 \\
Term $>37 \mathrm{wks})$ & 89 & 46.6 \\
Birth Weight & & \\
Low $<2.5 \mathrm{Kg}$ & 109 & 57.1 \\
Normal $>2.5 \mathrm{Kg}$ & 82 & 42.9 \\
Axillary temperature $\left({ }^{\circ} \mathrm{C}\right)$ & & \\
Low $<35.5$ & & \\
Normal 35.5 -37.5 & 7010912 & \\
High $>37.5$ & & \\
\hline A & &
\end{tabular}




\section{Continuation of table 1}

\begin{tabular}{lcl}
\hline Variable & Frequency(191) & Percentage(\%) \\
\hline $\begin{array}{l}\text { Respiratory rate (breaths/min) } \\
\text { Low }<40\end{array}$ & 21 & 0.16 \\
Normal $40-59$ & 25 & 5.4 \\
High $>60$ & 64 & 34.5 \\
Pulse rate (beats/min) & & \\
Low $<100$ & 4 & 2.1 \\
Normal $100-160$ & 175 & 91.6 \\
High $>160$ & 12 & 6.3 \\
Apgar Score at $\mathbf{5}$ min & & \\
Low $<7$ & 84 & 44.0 \\
Normal $>7$ & 107 & 56.0 \\
\hline
\end{tabular}

Table 2: Laboratory findings of neonates assessed for occurrence of UGIB

\begin{tabular}{|c|c|c|}
\hline Variable & Frequency(191) & Percentage $(\%)$ \\
\hline \multicolumn{3}{|l|}{ WBC count } \\
\hline Low $(<9,000 / \mu \mathrm{L})$ & 40 & 20.9 \\
\hline Normal $(9,000-30,000 / \mu \mathrm{L})$ & 138 & 72.3 \\
\hline High $(>30,000 / \mu \mathrm{L})$ & 13 & 6.8 \\
\hline \multicolumn{3}{|l|}{ Hemoglobin level (g/dl) } \\
\hline Low $(<15 \mathrm{~g} / \mathrm{dl})$ & 33 & 17.3 \\
\hline Normal $(>15 \mathrm{~g} / \mathrm{dl})$ & 158 & 82.7 \\
\hline \multicolumn{3}{|l|}{ Platelet count } \\
\hline Thrombocytopenia $(<150,000)$ & 23 & 12.0 \\
\hline Normal $>150,000$ & 168 & 88.0 \\
\hline \multicolumn{3}{|c|}{ Occult blood in gastric aspirates (Guaiac test) } \\
\hline Positive & 92 & 48.2 \\
\hline Negative & 99 & 51.8 \\
\hline \multicolumn{3}{|c|}{ Apt Test on occult blood positive gastric aspirates } \\
\hline Positive for swallowed blood & 48 & 52.2 \\
\hline Negative & 44 & 47.8 \\
\hline
\end{tabular}

\section{Discussion}

In this study, almost a quarter of the neonates developed UGIB, a figure that lies within the range of $5.5 \%-43.5 \%$ found by various studies ${ }^{3,7-10}$. The prevalence in this study is less than what some studies reported most probably because the neonates in this study had advanced gestation age and were less likely to be on mechanical ventilation and other invasive procedures. A higher figure of $43.5 \%{ }^{2}$ was reported among children diagnosed with stress ulceration, while Deerojanawong et al reported $51.8 \%$ in among children on mechanical ventilation, a recognized risk factor for $\mathrm{UGIB}^{5}$.

A closer proportion of $20 \%$ was reported by Kuusela et al ${ }^{9}$ while Cochran et al, found $25 \%$ of the 208 patients followed up developed $\mathrm{UGIB}^{11}$. Proportions as low as $6 \%$ have been reported in some studies ${ }^{12,13}$ which considered a general pediatric population. While ranitidine prophylaxis decreases the incidence of UGIB in critically ill children ${ }^{9,14,15}$, it is not known whether the prevalence in this study would have been lower than $23.0 \%$ had the study subjects received ranitidine prophylaxis against UGIB. As previously reported ${ }^{3,9,16}$, this study has supported the association between birth asphyxia and UGIB. UGIB in neonates with birth asphyxia has been attributed to stress of illness, which is a known risk for gastric ulceration occurring in up to $20 \%$ of patients cared for in the neonatal ICU 9 . Stress increases gastric acid secretion and plays a key role in ulceration in older children and adults ${ }^{17}$. In this study, most of the neonates who suffered from asphyxia were born after prolonged labor, had a low Apgar score and 
required resuscitation by bag and mask immediately after birth. Birth asphyxia, cyanosis in the neonate and neonatal seizures were independently associated with UGIB and no interaction between birth asphyxia, seizures and cyanosis was found during analysis. Most babies in this study developed UGIB on the $2^{\text {nd }}$ and $3^{\text {rd }}$ day of follow up.

Table 3: Diagnosis, Clinical and Laboratory findings associated with UGIB

\begin{tabular}{|c|c|c|c|c|}
\hline Variable & $\begin{array}{l}\text { Developed UGIB } \\
N=44(\%)\end{array}$ & $\begin{array}{l}\text { NO UGIB } \\
\mathrm{N}=147(\%)\end{array}$ & OR(95\% CI) & $P$ value \\
\hline Thrombocytopenia $(<150,000)$ & $10(22.7)$ & $13(8.8)$ & $3.0(1.2-7.6)$ & 0.013 \\
\hline Hemoglobin level $(<15 \mathrm{~g} / \mathrm{dl})$ & $8(18.2)$ & $25(17.0)$ & $1.1(0.5-2.6)$ & 0.857 \\
\hline Neonatal seizures & $8(18.2)$ & $2(1.4)$ & $15.9(3.0-85.5)$ & $<0.001$ \\
\hline Respiratory Distress Syndrome & $1(2.3)$ & $4(2.7)$ & $1.2(0.1-11.1)$ & 0.871 \\
\hline Birth asphyxia & $26(59.1)$ & $42(28.6)$ & $4.1(2.0-8.6)$ & $<0.001$ \\
\hline Neonatal jaundice & $6(13.6)$ & $16(10.9)$ & $1.3(0.5-3.5)$ & 0.617 \\
\hline Neonatal septicemia & $2(4.6)$ & $11(7.5)$ & $1.7(0.4-8.0)$ & 0.498 \\
\hline Small for gestation age & $3(6.8)$ & $17(11.6)$ & $1.8(0.5-6.4)$ & 0.368 \\
\hline Mothers age $<20$ years & $11(25.0)$ & $26(17.7)$ & $1.6(0.7-3.5)$ & 0.282 \\
\hline Vaginal Discharge & $21(47.7)$ & $45(30.6)$ & $2.1(1.0-4.2)$ & 0.037 \\
\hline Malaria in Pregnancy & $8(18.2)$ & 17(11.6) & $1.7(0.7-4.3)$ & 0.252 \\
\hline HIV exposure of the neonate & $8(18.2)$ & $25(17.0)$ & $1.1(0.4-2.6)$ & 0.857 \\
\hline Prolonged labor ( $>18$ hours) & $27(61.4)$ & $74(50.3)$ & $2.1(1.0-4.1)$ & 0.038 \\
\hline Low Apgar Score at $5 \mathrm{~min}$ & $28(63.6)$ & $56(38.1)$ & $2.9(1.4-5.8)$ & 0.003 \\
\hline $\begin{array}{l}\text { Baby resuscitated by bag and mask } \\
\text { after birth }\end{array}$ & $27(61.4)$ & $50(34.0)$ & $3.1(1.5-6.3)$ & 0.001 \\
\hline Preterm delivery $(<37$ weeks $)$ & $18(40.9)$ & $84(57.1)$ & $1.9(1.0-3.8)$ & 0.059 \\
\hline Hypothermia $(<35.5 \circ \mathrm{oC})$ & $19(43.2)$ & $51(34.7)$ & $1.4(0.7-2.8)$ & 0.311 \\
\hline Cyanosis in neonate & $8(18.2)$ & $10(6.8)$ & $5.1(1.8-14.4)$ & 0.001 \\
\hline Birth weight $>2500 \mathrm{gm}$ & $26(59.1)$ & $56(38.1)$ & $2.3(1.2-4.7)$ & 0.014 \\
\hline Respiratory rate $(>60 \mathrm{~b} / \mathrm{min})$ & $15(34.1)$ & $49(33.3)$ & $1.0(0.5-2.0)$ & 0.926 \\
\hline
\end{tabular}

Note:

$1.92 \%$ of the babies with birth asphyxia were term deliveries.

2. Of the 23 study subjects with thrombocytopenia; only 10 developed UGIB. Of these 10 subjects, 6 had mild thrombocytopenia $(100,000-150,000), 3$ had moderate thrombocytopenia $(50,000-100,000)$ and only 1 had severe thrombocytopenia $(<50,000)$.

Table 4: Factors independently associated with UGIB

\begin{tabular}{llllll}
\hline Variable & $\begin{array}{l}\text { Developed } \\
\text { UGIB } \\
\text { N= 44 (\%) }\end{array}$ & $\begin{array}{l}\text { COR* } \\
\mathbf{( 9 5 \%} \mathbf{C I})\end{array}$ & P value & AOR*(95\% CI) & P value \\
\hline $\begin{array}{l}\text { Preterm delivery } \\
(<37 \text { weeks) }\end{array}$ & $18(40.9)$ & $2.0(1.0-3.9)$ & 0.059 & $3.3(1.0-11.5)$ & 0.059 \\
$\begin{array}{l}\text { Cyanosis in neonate } \\
\text { Neonatal seizures }\end{array}$ & $8(18.2)$ & $5.1(1.8-14.4) \mathbf{0 . 0 0 1}$ & $5.8(1.8-19.1)$ & $\mathbf{0 . 0 0 4}$ \\
$\mathbf{0 . 0 0 4}$ & $15.9(3.0-85.5)$ & $<\mathbf{0 . 0 0 1}$ & $12.6(2.3-70.5)$ \\
Birth asphyxia & $26(59.1)$ & $4.1(2.0-8.6)$ & $<\mathbf{0 . 0 0 1}$ & $6.3(1.9-21.6)$ & $\mathbf{0 . 0 0 3}$ \\
\hline
\end{tabular}


All the neonates in this study received routine vitamin $\mathrm{K}$ injection on admission, a factor that could have reduced the risk of bleeding due to deficiency of vitamin $\mathrm{K}$ dependent clotting factors. In this study, thrombocytopenia was found to occur among $12 \%$, of the neonates, a figure that is much lower than the reported range of $18-35 \%{ }^{18-20}$. Similar to previous studies ${ }^{1,9}$, this study found that thrombocytopenia was significantly associated with UGIB. However, reasonable conclusions at different degrees of thrombocytopenia could not be made, since the number for the different levels of thrombocytopenia were few. Christensen et al attributed thrombocytopenia in neonates (especially ELBW) to the effect of early onset infection, thrombi, DIC, and severe hemorrhages ${ }^{19}$. This study however did not establish an association between septicemia and UGIB or between septicemia and thrombocytopenia. In this study, all subjects received routine prophylactic antibiotics, an intervention that could have reduced the prevalence of septicemia and thrombocytopenia. While studies show that maternal medication (aspirin, heparin, indomethacin) increase the risk of UGIB in the neonates ${ }^{16,21}$, this study did not find any such association, partly because of the small numbers since only 2 mothers were on heparin, 2 aspirin and none on warfarin.

\section{Conclusion}

In the first seven days of life, UGIB occurred in 1 in 4 neonates admitted to SCU of Mulago Hospital. Factors independently associated with UGIB include birth asphyxia, cyanosis in the neonate and neonatal seizures.

\section{Acknowledgement}

We thank Save the Children Uganda for the financial support for this work. Many thanks go to the research assistants Damalie, Liz and Immaculate, the laboratory technicians Hosea and Wilson, and statistician Deo and Leonard and all staff of the SCU for their hard work and co-operation that made this study successful. Lastly, we are grateful to all neonates and their parents/caregivers for accepting to participate in this study.

This work was part of a thesis submitted by Dr. Ombeva in partial fulfillment of the requirements for Makerere University Masters of Medicine (M.Med) in Paediatrics and Child Health.

\section{References}

1. Arora NK, Ganguly S, Mathur P, Ahuja A, Patwari A. Upper gastrointestinal bleeding: etiology and management. Indian J Pediatr 2002;69:155-68.

2. Chookhuan Nithiwathanapong, Reungrongrat Sanit, Ukarapol Nuthapong. Prevalence and risk factors of stress-induced gastrointestinal bleeding in critically ill children. World J Gastroenterol 2005;11:6839-42.

3. Mahamadou Chaïbou, Marisa Tucci, MarcAndré Dugas, Catherine Ann Farrell, François Proulx, Lacroix J. Clinically Significant Upper Gastrointestinal Bleeding Acquired in a Pediatric Intensive Care Unit: A Prospective Study. Pediatrics 1998;102:933-8

4. Neonatal and perinatal mortality, Country, regional and global estimates. WHO Press, 2006. (Accessed 2nd August, 2010, at http:// whqlibdoc.who.int/publications / 2006/ 9241563206_eng.pdf.)

5. Deerojanawong Jitladda, Peongsujarit Danayawan, Vivatvakin Boosba, Prapphal Nuanchan. Incidence and risk factors of upper gastrointestinal bleeding in mechanically ventilated children Pediatric Critical Care Medicine 2009;10:91-5.

6. Formula for Calculating Sample size for difference in proportions. July 2010. (Accessed at http://www.openepi.com/OE2.3/Menu/ OpenEpiMenu.htm.)

7. Cook DJ, Fuller HD, Guyatt GH, et al. Risk factors for gastrointestinal bleeding in critically ill patients. Canadian Critical Care Trials Group. N Engl J Med 1994;330:377-81.

8. Fusamoto H, Hagiwara $\mathrm{H}$, Meren $\mathrm{H}$, et al. A clinical study of acute gastrointestinal hemorrhage associated with various shock states. Am J Gastroenterol 1991;86:429-33.

9. Kuusela AL, Maki M, Ruuska T, Laippala P. Stress-induced gastric findings in critically ill newborn infants: frequency and risk factors. Intensive Care Med 2000;26:1501-6.

10. Pimentel M, Roberts DE, Bernstein CN, Hoppensack M, DR D. Clinically significant gastrointestinal bleeding in critically ill patients in an era of prophylaxis. Am J Gastroenterol 2000;95:2801-6

11. Cochran EB, Phelps SJ, Tolley EA, Stidham GL. Prevalence of, and risk factors for, upper gastrointestinal tract bleeding in critically ill 
pediatric patients. Crit Care Med 1992 Nov;20:1519-23.

12. Lacroix J, Nadeaus D, Laberge S. Frequency of upper gastrointestinal bleeding in a pediatric intensive care unit. Crit Care Med 1992;8:35-42.

13. Liebman M, Thaler MM, Buvanover Y. Endoscopic evaluation of upper gastrointestinal bleeding in the newborn. Am J Gastroenterol 1978;69:607-8.

14. Ludovic, Reveiz, Rafael, et al. Stress ulcer, gastritis, and gastrointestinal bleeding prophylaxis in critically ill pediatric patients: A systematic review. Pediatric Critical Care Medicine: 2010 Jan 11:124-32.

15. Pourarian S, Imani B, Imanieh MH. Prophylactic Ranitidine in Prevention of GI Bleeding in Neonatal Intensive Care Units. Iran J Med Si 2005; Vol 30:178-81.

16. Lazzaroni M, Petrillo M, Tornaghi R, et al. Upper GI Bleeeding in Healthy Full-Term Infants: A case - Control Study. The American Journal of Gastroenterology 2002;97:89-94.
17. Maki M, Russka T, Kussela AL. High prevalence of asymptomatic esopHageal and gastric lesions in preterm infants in intensive care. Crit care Med 1993;21:1863-8.

18. Bonifacio Lea, Petrova Anna, Nanjundaswamy Shakuntala, Mehta Rajeev. Thrombocytopenia Related neonatal outcomes in Preterms. Indian J Pediatr 2007;74:269-74.

19. Christensen RD, Henry E, Wiedmeier SE, et al. Thrombocytopenia among extremely low birth weight neonates: data from a multihospital healthcare system. Journal of Perinatology 2006;26:348-53.

20. 20. Roberts I, Murray NA. Review; Neonatal thrombocytopenia: causes and management. Arch Dis Child Fetal Neonatal Ed 2003;88:F359F64.

21. López-Herce J, Dorao P, Elola P, Delgado MA, Ruza F, Madero R. Frequency and prophylaxis of upper gastrointestinal hemorrhage in critically ill children: a prospective study comparing the efficacy of almagate, ranitidine and sucralfate. Crit Care Med 1992;20:1082-9. 